Original paper

\title{
Hyaluronic acid as a potential marker for assessment of fibrosis regression after direct acting antiviral drugs in chronic hepatitis $\mathrm{C}$ patients
}

\author{
Eman Rewisha', Tary Salman'1, Omkolsoum Alhaddad', Gamal Abo Raia², Mary Naguib², Shymaa Rashad', \\ Ahmed Abdelfattah', Khaled Metwally', Eman Abdelsameea' \\ ${ }^{1}$ Hepatology and Gastroenterology Department, National Liver Institute, Menoufia University, Egypt \\ ${ }^{2}$ Clinical Pathology Department, National Liver Institute, Menoufia University, Egypt
}

\begin{abstract}
Introduction: Fibrosis is an inevitable complication of chronic hepatitis C virus (HCV) infection. Direct acting antivirals (DAAs) radically treated HCV and were suggested to ameliorate fibrosis. Silymarin (a natural herbal remedy) was proposed to further decrease hepatic inflammation and fibrosis. Consequently, serial monitoring of liver fibrosis status by different biomarkers is needed.

Aim of the study: To assess hyaluronic acid (HA) as a potential marker of fibrosis regression after DAAs in chronic HCV patients; in addition, to evaluate silymarin as an agent that, beside DAAs, could further improve fibrosis.

Material and methods: Two groups were included (150 patients each). Group 1 received DAAs only, while group 2 received DAAs followed by silymarin. Hyaluronic acid and FIB4 score were assessed at baseline before treatment and 1 year after inclusion in the study.

Results: We found that DAA therapy alone or in combination with silymarin resulted in a significant reduction in serum HA level. However, the latter case showed a statistically significantly greater reduction $(p=0.034)$. Mean \pm SD of serum HA level was $211.8 \pm 179.9$ and $143.3 \pm 123.9 \mu \mathrm{g} / \mathrm{l}$ before and one year after inclusion respectively in group $1(p=0.001)$ and also, its level decreased significantly in group 2 from $188.3 \pm 211.8 \mu \mathrm{g} / \mathrm{l}$ before receiving DAAs to $126.4 \pm 136.9 \mu \mathrm{g} / \mathrm{l}$ at one year after inclusion $(p=0.001)$. There was no significant difference between the 2 studied groups as regards FIB-4 at 1 year after inclusion $(p=0.103)$.

Conclusions: Hyaluronic acid might be a sensitive marker for monitoring fibrosis regression in treated chronic HCV patients. Adding silymarin to treatment protocols could ameliorate the fibrosis status.
\end{abstract}

Key words: chronic HCV, hyaluronic acid, FIB-4, fibrosis, regression.

Address for correspondence:

Eman Abdelsameea, Assoc. Prof., National Liver Institute, Menoufia University, Egypt, e-mail: eabdelsameea@liver-eg.org

\section{Introduction}

Hepatitis $\mathrm{C}$ virus (HCV) is a major health problem and a leading cause of cirrhosis and hepatocellular carcinoma [1]. Every year, 3 to 4 million people are newly infected with HCV [2]. The highest prevalence of HCV was in Egypt with $>5$ million persons having chronic HCV infection [1]. A revolutionary reduction of the HCV epidemic occurred with the introduction of direct acting antivirals (DAAs) effective for genotype 4 [3].
Treatment of HCV with oral DAAs resulted in high cure rates in different clinical settings including elderly patients, patients with end-stage renal disease and those with cirrhosis [4]. However, several challenges remain, including hard to cure cirrhosis [5].

Chronic hepatitis C occurs in $70-80 \%$ of those infected with the virus [6]. Liver fibrosis is a common consequence of chronic hepatitis C. It is characterized by continuous deposition of extracellular matrix (ECM) leading to scar formation [7]. This is attributed to in- 
flammatory cytokine signaling pathways and stimulation of the stellate cells. Eventually, liver cirrhosis and portal hypertension develop if left untreated [8].

Silymarin is a mixture of flavonolignans obtained from milk thistle and natural herbal therapy [9]. It is considered as an anti-fibrogenic agent due to its effect in decreasing inflammatory reactions. Also, it has membrane-stabilizing, antioxidant activity and stimulates hepatocyte regeneration [10]. The noninvasive diagnosis of liver fibrosis is still progressing. It could be performed through serum markers, whether direct or indirect, or through physical diagnosis by noninvasive ultrasound elastography [11].

Hyaluronic acid (HA) is a fundamental constituent of the extracellular matrix, which is predominantly produced by hepatic stellate cells and degraded by sinusoidal endothelial cells. Some studies have shown that it could correlate with the histological stages of liver fibrosis in chronic liver diseases [12]. Thus, this study aimed to evaluate the serum level of HA as a non-invasive marker for detection of fibrosis regression after DAAs in chronic hepatitis $C$ infected patients, and also to evaluate silymarin as an agent that, beside DAAs, could further ameliorate fibrosis.

\section{Material and methods}

\section{Study population}

This prospective study included 2 groups of patients diagnosed as having HCV-related chronic liver disease based on laboratory and imaging parameters. They were recruited from the virology clinic, HepatoGastroenterology Department at the National Liver Institute Hospital, Menoufia University.

Ethical committee approval of the National Liver Institute was received and informed consent was obtained from all patients before inclusion in the study.

Patients were selected to represent all stages of liver fibrosis from F0 to F4, having compensated disease and achieved sustained virological response to oral antiHCV treatment. Sustained virological response (SVR) is identified as undetectable HCV RNA in serum or plasma 12 weeks (SVR12) or 24 weeks (SVR24) following the end of treatment, as detected by a sensitive molecular method with a lower limit of detection $\leq 15 \mathrm{IU} / \mathrm{ml}$ ) [13].

Patients with hepatocellular carcinoma (HCC) or who were clinically decompensated were excluded. Also, patients with a Child-Pugh score $>7$, serum creatinine $>1.5 \mathrm{mg} / \mathrm{dl}$ or platelet count $<50,000 / \mathrm{mm}^{3}$ were excluded. Patients aged less than 18 years or older than 75 years, pregnant patients or those who were unable to use effective contraception were not enrolled.
The first group (group 1) and the second group (group 2) received oral antiHCV treatment and achieved a sustained virological response. Patients in group 2 received fixed oral dosing of silymarin $(420 \mathrm{mg}$ daily in three divided doses) for 9 months after the end of antiHCV treatment.

\section{Treatment protocols of different groups}

Oral antiHCV regimens were tailored according to the National Committee for Control of Viral Hepatitis (NCCVH) protocol.

The treatment protocol of group 1 was: 45 patients (30\%) were treated with sofosbuvir and daclatasvir (SOF/DAC), 73 (48.7\%) patients were treated with sofosbuvir, daclatasvir and ribavirin (SOF/DAC/RBV) and $15(10 \%)$ patients were treated with sofosbuvir and simeprevir (SOF/SIM), 17 (11.3\%) were treated with sofosbuvir, simeprevir and ribavirin (SOF/SIM/RBV). One hundred and thirty two (88\%) patients were treated with oral anti-HCV treatment for 12 weeks, while eighteen $(12 \%)$ patients were treated with oral anti$\mathrm{HCV}$ treatment for 24 weeks.

The treatment protocol of group 2 was: 22 patients (14.7\%) were treated with SOF/DAC, 38 (25.3\%) patients were treated with SOF/DAC/RBV, and 51 (34\%) patients were treated with SOF/SIM, 39 (26\%) were treated with SOF/SIM/RBV. One hundred and forty two $(94.7 \%)$ patients were treated with oral anti-HCV treatment for 12 weeks, while eight (5.3\%) patients were treated with oral anti-HCV treatment for 24 weeks.

\section{Clinical examination and laboratory investigations}

All patients were subjected to: 1) thorough history taking, 2) complete clinical examination, 3) laboratory investigations including complete blood count (CBC), liver function tests; aspartate aminotransferase (AST), alanine aminotransferase (ALT), prothrombin concentration and international normalized ratio (INR), total bilirubin, albumin, viral markers: anti-HCV antibody and hepatitis B surface antigen (HBsAg), quantification of HCV RNA level at the beginning of treatment, after one month, at the end of treatment and 3 months after the end of treatment; serum creatinine and $\alpha$-fetoprotein (AFP) were measured at baseline. Measurement of fasting blood sugar level or $\mathrm{HbA}_{1 \mathrm{c}}$ was done if the patient was diabetic.

Liver tests, serum creatinine, fasting blood sugar, HCV Ab, HBsAg and AFP were measured using a Cobas 6000 analyzer (c501 module and e601 module, Roche Diagnostics GmbH, D-68305 Mannheim, Ger- 
many). The prothrombin test was done using Sysmex CS-1600 (Sysmex Europe GmbH, Bornbarch 1, 22848 Norderstedt, Germany). Complete blood picture was done using Sysmex XT 1800i (Sysmex Corporation, Kobe 651-0073, Japan). HCV RNA PCR was measured by use of COBAS AmpliPrep/COBAS TaqMan (Roche Diagnostics Ltd., Germany) with a detection limit of $15 \mathrm{IU} / \mathrm{ml}$. HCV RNA levels are expressed in IU/ml.

\section{Abdominal ultrasonography}

It was done to study liver parenchyma, size, outlines as well as the gallbladder, portal and hepatic veins. Also spleen size, splenic vein diameter and any collateral and the presence of ascites or focal lesions were evaluated.

\section{Assessment of fibrosis}

\section{FIB-4 score}

It was calculated before and after treatment using Sterling's formula [14]:

Age (years) $\times$ AST $($ IU $/ \mathrm{l}) /\left(\right.$ platelet count $\left(\times 10^{9} / \mathrm{l}\right)$ $\times \sqrt{ } \operatorname{ALT}(\mathrm{IU} / \mathrm{l}))$.

The FIB-4 index uses cut-off values of 1.45 and 3.25 to rule out or rule in significant fibrosis, respectively. No or moderate fibrosis (F0-F1-F2-F3) is considered when the score is $<1.45$, while extensive fibrosis or cirrhosis (F4-F5-F6) is considered when the score is $>3.25$ [15].

\section{Serum hyaluronic acid concentration}

It was measured before and after treatment. Human HA level was measured in serum using a sandwich enzyme-linked immunosorbent assay (ELISA) kit from NOVA according to the manufacturer's instructions.

\section{Statistical analysis}

Results were statistically analyzed using SPSS 22.0 (IBM Corp., Armonk, NY). For summarizing quantitative data they were presented in the form of mean, standard deviation (SD), and range, and qualitative data were presented in the form of numbers and percentages. Chi-square test $\left(\chi^{2}\right)$ was used to study the association between two qualitative variables. Fisher's exact test was used for $2 \times 2$ tables when the expected cell count of more than $25 \%$ of cases was less than 5 . Student's $t$-test is a test of significance used for comparison between two groups in the case of quantitative variables. The Mann-Whitney test is a test of significance used for comparison between two groups in the case of quantitative variables when the data are not normally distributed. The Wilcoxon signed rank test is a test of significance used for comparison between two related groups not normally distributed in the case of quantitative variables. McNemar's test assesses the significance of the difference between two correlated proportions, such as might be found in the case where the two proportions are based on the same sample of subjects or on matched-pair samples. A $p$ value of $\geq 0.05$ was considered statistically non-significant, while a $p$ value of $<0.05$ was considered statistically significant.

\section{Results}

Group 1 included 101 (67.3\%) males and 49 (32.7\%) females with a mean age of $50.7 \pm 11.2$ years, while group 2 included $88(58.7 \%)$ males and $62(41.3 \%)$ females with a mean age of $48.3 \pm 10.8$ years. No statistically significant differences were found between the two studied groups regarding their age or gender $(p>0.05)$.

Comparison of laboratory parameters was performed at baseline, end of treatment, 3 months after treatment (SVR) and one year after inclusion in group 1 (Table 1). By comparing different means of $\mathrm{CBC}$ and liver and kidney function tests, we found a statistically significant increase in platelets as its mean \pm SD was $174.9 \pm 86.3$ and $181.4 \pm 72.2 \times 10^{3} / \mu \mathrm{l}$ before treatment and one year after inclusion respectively in group 1 $(p<0.05)$. Similarly, there were statistically significant differences in albumin, ALT, AST and INR before treatment and one year after inclusion in group 1.

Comparison of laboratory parameters at baseline, end of treatment, 3 months after treatment (SVR) and one year after inclusion in group 1 (Table 2). By comparing different means of $\mathrm{CBC}$ and liver and kidney function tests, we found statistically significant differences in albumin, ALT, AST and INR before treatment and one year after inclusion in group 1.

Further, there was a statistically significant improvement in synthetic function of the liver manifested by significant increase in serum albumin level one year after inclusion in both groups and significant reduction of INR at end of treatment, SVR and 1 year after inclusion in the study in both groups, but the end of treatment value showed no significance in group 1 (Tables 1 and 2).

\section{Studying diagnostic performance of serum hyaluronic acid}

We found that serum HA could be a sensitive marker for reduction of fibrosis after different protocols of treatment. The mean $\pm \mathrm{SD}$ of serum HA level 
Table 1. Comparison of laboratory parameters at pretreatment, at the end of treatment, 3 months after treatment and one year after inclusion in the study in group $1(n=150)$

\begin{tabular}{|c|c|c|c|c|c|c|}
\hline \multirow[t]{2}{*}{$\begin{array}{l}\text { Studied } \\
\text { variables }\end{array}$} & \multicolumn{4}{|c|}{$\begin{array}{l}\text { Group } 1 \\
(n=150)\end{array}$} & \multirow[t]{2}{*}{ Wilcox on test } & \multirow[t]{2}{*}{$P$ value } \\
\hline & $\begin{array}{l}\text { Pre-treatment } \\
\text { Mean } \pm S D\end{array}$ & $\begin{array}{l}\text { End of treatment } \\
\text { Mean } \pm S D\end{array}$ & $\begin{array}{c}3 \text { months post treatment } \\
\text { Mean } \pm S D\end{array}$ & $\begin{array}{c}1 \text { year after inclusion } \\
\text { Mean } \pm S D\end{array}$ & & \\
\hline $\mathrm{HB}(\mathrm{g} / \mathrm{dl})$ & $14.2 \pm 9.21$ & $12.2 \pm 1.61$ & $13.8 \pm 1.55$ & $14.1 \pm 1.53$ & $\begin{array}{l}8.78 \\
0.52 \\
1.69\end{array}$ & $\begin{array}{c}p 1: 0.001 \text { * } \\
p 2: 0.600 \\
p 3: 0.092\end{array}$ \\
\hline $\begin{array}{l}\text { WBCs } \\
\left(\times 10^{3} / \mu l\right)\end{array}$ & $6.36 \pm 2.09$ & $6.40 \pm 1.90$ & $6.91 \pm 2.07$ & $6.94 \pm 1.71$ & $\begin{array}{l}0.805 \\
2.26 \\
1.69\end{array}$ & $\begin{array}{c}p 1: 0.421 \\
p 2: 0.026^{*} \\
p 3: 0.509\end{array}$ \\
\hline $\begin{array}{l}\text { Platelets } \\
\left(\times 10^{3} / \mu \mathrm{l}\right)\end{array}$ & $174.9 \pm 86.3$ & $175.2 \pm 69.9$ & $180.2 \pm 69.3$ & $181.4 \pm 72.2$ & $\begin{array}{l}0.03 \\
1.77 \\
0.15 \\
\end{array}$ & $\begin{array}{l}p 1: 0.973 \\
p 2: 0.076 \\
p 3: 0.001^{*}\end{array}$ \\
\hline $\begin{array}{l}\text { Total } \\
\text { bilirubin } \\
(\mathrm{mg} / \mathrm{dl})\end{array}$ & $0.77 \pm 0.32$ & $1.28 \pm 0.81$ & $0.75 \pm 0.59$ & $0.80 \pm 0.78$ & $\begin{array}{l}8.16 \\
0.36 \\
0.44 \\
\end{array}$ & $\begin{array}{c}p 1: 0.001^{*} \\
p 2: 0.715 \\
p 3: 0.663\end{array}$ \\
\hline $\begin{array}{l}\text { Direct } \\
\text { bilirubin } \\
(\mathrm{mg} / \mathrm{dl})\end{array}$ & $0.32 \pm 0.23$ & $0.56 \pm 0.46$ & $0.35 \pm 0.34$ & $0.37 \pm 0.50$ & $\begin{array}{l}6.62 \\
0.36 \\
0.44\end{array}$ & $\begin{array}{c}p 1: 0.001 \text { * } \\
p 2: 0.371 \\
p 3: 0.266\end{array}$ \\
\hline Albumin (g/dl) & $3.82 \pm 0.55$ & $3.83 \pm 0.56$ & $3.91 \pm 0.47$ & $4.69 \pm 4.90$ & $\begin{array}{l}0.16 \\
1.74 \\
2.16\end{array}$ & $\begin{array}{c}p 1: 0.876 \\
p 2: 0.081 \\
p 3: 0.031^{*}\end{array}$ \\
\hline AST (U/l) & $56.8 \pm 40.4$ & $38.4 \pm 22.1$ & $37.0 \pm 18.0$ & $27.7 \pm 15.1$ & $\begin{array}{l}7.34 \\
4.48 \\
9.57\end{array}$ & $\begin{array}{l}p 1: 0.001 \text { * } \\
p 2: 0.001^{*} \\
p 3: 0.001^{*}\end{array}$ \\
\hline ALT (U/l) & $60.5 \pm 44.5$ & $37.8 \pm 20.7$ & $34.6 \pm 16.5$ & $26.7 \pm 14.4$ & $\begin{array}{l}7.61 \\
1.32 \\
9.63\end{array}$ & $\begin{array}{l}p 1: 0.001 \text { * } \\
p 2: 0.001 \text { * } \\
p 3: 0.001 \text { * }\end{array}$ \\
\hline INR & $1.60 \pm 1.31$ & $1.50 \pm 0.26$ & $1.10 \pm 0.14$ & $1.11 \pm 0.12$ & $\begin{array}{l}1.61 \\
9.75 \\
16.6\end{array}$ & $\begin{array}{l}p 1: 0.168 \\
p 2: 0.001^{*} \\
p 3: 0.001^{*}\end{array}$ \\
\hline Creatinine $(\mathrm{mg} / \mathrm{dl})$ & $0.88 \pm 0.78$ & $0.75 \pm 0.26$ & $0.77 \pm 0.27$ & $0.74 \pm 0.26$ & $\begin{array}{l}3.48 \\
1.25 \\
0.98\end{array}$ & $\begin{array}{l}p 1: 0.175 \\
p 2: 0.209 \\
p 3: 0.327\end{array}$ \\
\hline
\end{tabular}

AST - aspartate transaminase, ALT - alanine transaminase, HB - hemoglobin, WBCs - white blood cells, INR - International Normalized Ratio, p1 - comparison between before treatment and at the end of treatment, p2 - comparison between before treatment and 3 months after treatment, $\mathrm{p3}$ - comparison between before treatment and one year after inclusion in the study

was $211.8 \pm 179.9 \mu \mathrm{g} / \mathrm{l}$ before treatment and its level decreased significantly to $143.3 \pm 123.9 \mu \mathrm{g} / \mathrm{l}$ after one year of inclusion in the study $(p=0.001)$ in group 1 . Also, we found that the mean \pm SD of serum HA levels showed a significant reduction in group 2 . The mean \pm SD of serum HA level was $188.3 \pm 211.8 \mu \mathrm{g} / \mathrm{l}$ before treatment and $126.4 \pm 136.9 \mu \mathrm{g} / \mathrm{l}$ after treatment $(p=0.001)$, as shown in Table 3 .

Further, HA could be a sensitive indicator for reduction of moderate to advanced fibrosis after treatment. As in group 1 patients, HA decreased significantly from $309.0 \pm 152.2 \mu \mathrm{g} / \mathrm{l}$ before receiving DAAs to $203.3 \pm 116.2 \mu \mathrm{g} / \mathrm{l}$ after treatment $(p<0.001)$. Also in group 2 patients, HA decreased significantly from
$337.4 \pm 213.8 \mu \mathrm{g} / \mathrm{l}$ before receiving DAAs and silymarin to $214.4 \pm 148.2 \mu \mathrm{g} / \mathrm{l}(p<0.001)$.

\section{Studying fibrosis status according to FIB-4 before and after treatment}

Comparison of FIB-4 before treatment, end of treatment, SVR and at one year after inclusion in the study in groups 1 and 2 revealed that there was a significant difference between FIB- 4 before treatment and SVR as the mean \pm SD level decreased from $2.81 \pm 2.49$ before treatment to $2.47 \pm 2.10$ at $\operatorname{SVR}(p=0.032)$ (Table 4). As regards group 2, there was a reduction in 
Table 2. Comparison of laboratory parameters at pretreatment, end of treatment, 3 months after treatment and one year after inclusion in the study in group 2

\begin{tabular}{|c|c|c|c|c|c|c|}
\hline \multirow[t]{2}{*}{ Studied variables } & \multicolumn{6}{|c|}{ Group $2(n=150)$} \\
\hline & $\begin{array}{c}\text { Before } \\
\text { treatment } \\
\text { Mean } \pm S D\end{array}$ & $\begin{array}{c}\text { End of } \\
\text { treatment } \\
\text { Mean } \pm S D\end{array}$ & $\begin{array}{c}\text { SVR } \\
\text { Mean } \pm S D\end{array}$ & $\begin{array}{c}1 \text { year after } \\
\text { inclusion } \\
\text { Mean } \pm S D\end{array}$ & Wilcox on test & $P$ value \\
\hline $\mathrm{HB}(\mathrm{g} / \mathrm{dl})$ & $14.2 \pm 8.21$ & $12.2 \pm 1.60$ & $13.5 \pm 1.60$ & $13.7 \pm 1.84$ & $\begin{array}{l}9.00 \\
1.02 \\
1.00\end{array}$ & $\begin{array}{c}p 1: 0.001^{*} \\
p 2: 0.306 \\
p 3: 0.315\end{array}$ \\
\hline WBCs $\left(\times 10^{3} / \mu \mathrm{l}\right)$ & $8.64 \pm 9.99$ & $6.76 \pm 2.13$ & $6.44 \pm 2.01$ & $6.62 \pm 2.05$ & $\begin{array}{l}0.184 \\
0.983 \\
0.854\end{array}$ & $\begin{array}{l}p 1: 0.854 \\
p 2: 0.326 \\
p 3: 0.640\end{array}$ \\
\hline 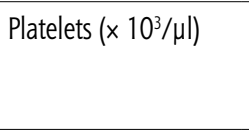 & $182.8 \pm 67.8$ & $186.6 \pm 68.3$ & $188.1 \pm 69.2$ & $190.9 \pm 73.6$ & $\begin{array}{l}2.78 \\
1.98 \\
2.65 \\
\end{array}$ & $\begin{array}{c}p 1: 0.005^{*} \\
p 2: 0.503 \\
p 3: 0.734\end{array}$ \\
\hline Total bilirubin (mg/dl) & $0.74 \pm 0.35$ & $1.14 \pm 0.63$ & $0.84 \pm 0.82$ & $0.83 \pm 0.5$ & $\begin{array}{l}7.63 \\
1.37 \\
1.69 \\
\end{array}$ & $\begin{array}{c}p 1: 0.001^{*} \\
p 2: 0.170 \\
p 3: 0.091\end{array}$ \\
\hline Direct bilirubin (mg/dl) & $0.30 \pm 0.40$ & $0.97 \pm 5.22$ & $0.35 \pm 0.43$ & $0.31 \pm 0.20$ & $\begin{array}{l}7.89 \\
6.95 \\
6.32 \\
\end{array}$ & $\begin{array}{c}p 1: 0.001 \text { * } \\
p 2: 0.297 \\
p 3: 0.784\end{array}$ \\
\hline Albumin (gm/dl) & $3.82 \pm 0.45$ & $3.91 \pm 0.46$ & $3.86 \pm 0.56$ & $4.60 \pm 4.88$ & $\begin{array}{l}1.71 \\
1.25 \\
1.95\end{array}$ & $\begin{array}{c}\text { p1: } 0.087 \\
\text { p2: } 0.209 \\
\text { p3: } 0.002^{*}\end{array}$ \\
\hline AST (U/I) & $54.3 \pm 41.5$ & $35.5 \pm 15.0$ & $35.1 \pm 17.8$ & $26.6 \pm 12.3$ & $\begin{array}{l}7.19 \\
4.66 \\
8.89 \\
\end{array}$ & $\begin{array}{l}p 1: 0.001^{*} \\
p 2: 0.001^{*} \\
p 3: 0.001^{*}\end{array}$ \\
\hline ALT (U/I) & $56.2 \pm 43.4$ & $34.3 \pm 16.7$ & $35.6 \pm 18.5$ & $24.4 \pm 10.5$ & $\begin{array}{c}6.93 \\
0.523 \\
9.35\end{array}$ & $\begin{array}{c}p 1: 0.001^{*} \\
p 2: 0.601 \\
p 3: 0.001^{*}\end{array}$ \\
\hline INR & $1.71 \pm 0.81$ & $1.12 \pm 0.10$ & $1.10 \pm 0.15$ & $1.09 \pm 0.10$ & $\begin{array}{l}29.8 \\
10.5 \\
30.3\end{array}$ & $\begin{array}{l}p 1: 0.002^{*} \\
p 2: 0.001^{*} \\
p 3: 0.001^{*}\end{array}$ \\
\hline Creatinine (mg/dl) & $0.82 \pm 0.18$ & $0.75 \pm 0.25$ & $0.74 \pm 0.24$ & $0.71 \pm 0.25$ & $\begin{array}{c}3.11 \\
0.522 \\
3.88\end{array}$ & $\begin{array}{c}p 1: 0.002^{*} \\
p 2: 0.601 \\
p 3: 0.289\end{array}$ \\
\hline
\end{tabular}

AST - aspartate transaminase, ALT - alanine transaminase, HB - hemoglobin, WBCS - white blood cells, INR - International Normalized Ratio, S - serum, p1 - comparison between before treatment and at the end of treatment, p2 - comparison between before treatment and 3 months post treatment, p3 - comparison between before treatment and one year after inclusion in the study

Table 3. Comparison of serum hyaluronic acid (HA) before treatment and at one year after inclusion in the study in groups 1 and 2

\begin{tabular}{lcccc}
\hline Studied variable & $\begin{array}{c}\text { Before treatment } \\
\text { Mean } \pm \text { SD }\end{array}$ & $\begin{array}{c}\text { 1 year after inclusion } \\
\text { Mean } \pm \text { SD }\end{array}$ & Wilcoxon test & P value \\
\hline $\begin{array}{l}\text { Group } 1(n=150) \\
\text { Hyaluronic acid }(\mu \mathrm{g} / \mathrm{d})\end{array}$ & $211.8 \pm 179.9$ & $143.3 \pm 123.9$ & 7.91 & $0.001^{*}$ \\
\hline $\begin{array}{l}\text { Group } 2(n=150) \\
\text { Hyaluronic acid }(\mu \mathrm{g} / \mathrm{d})\end{array}$ & $188.3 \pm 211.8$ & $126.4 \pm 136.9$ & 6.76 & $0.001^{*}$ \\
\hline
\end{tabular}

FIB-4 values from $2.41 \pm 2.73$ before treatment to 2.00 \pm 1.63 , but it was not significant $(p=0.061$ ) (Table 4$)$.

We studied serum HA level one year after inclusion in the study in the two groups (Table 5). We found that the mean \pm SD of serum HA level was $143.3 \pm 123.9 \mu \mathrm{g} / 1$ in group 1 patients (who received DAAs only) and
$126.4 \pm 136.9 \mu \mathrm{g} / \mathrm{l}$ in group 2 patients (who received DAAs and silymarin) $(p=0.034)$. This was not the case for FIB-4; it showed no significant difference between the two studied groups at end of treatment and at one year after inclusion in the study $(p=0.066,0.103)$, as shown in Table 6. 
Table 4. Comparison of FIB-4 before treatment, end of treatment, SVR and at one year after inclusion in the study in groups 1 and 2

\begin{tabular}{lcccccc}
$\begin{array}{l}\text { Studied } \\
\text { variable }\end{array}$ & $\begin{array}{c}\text { Before treatment } \\
\text { Mean } \pm \text { SD }\end{array}$ & $\begin{array}{c}\text { End of treatment } \\
\text { Mean } \pm \text { SD }\end{array}$ & $\begin{array}{c}\text { SVR } \\
\text { Mean } \pm \text { SD }\end{array}$ & $\begin{array}{c}\text { 1 year after inclusion } \\
\text { Mean } \pm \text { SD }\end{array}$ & Wilcoxon test & $P$ value \\
\hline Group 1 & $2.81 \pm 2.49$ & $2.54 \pm 2.18$ & $2.47 \pm 2.10$ & $2.76 \pm 2.46$ & 1.94 & $p 1: 0.052$ \\
$(n=150)$ & & & & & 2.14 & $p 2: 0.032^{*}$ \\
FIB-4 & & & & & 1.82 & $p 3: 0.062$ \\
& & & & & 0.82 & $p 4: 0.413$ \\
\hline Group 2 & $2.41 \pm 2.73$ & $2.07 \pm 1.84$ & $2.00 \pm 1.63$ & $2.40 \pm 2.74$ & 1.91 & $p 1: 0.056$ \\
$(n=150)$ & & & & & 1.87 & $p 2: 0.061$ \\
FIB-4 & & & & & 1.21 & $p 3: 0.122$ \\
& & & & & 1.22 & $p 4: 0.221$ \\
\hline
\end{tabular}

*Significant, -SVR - sustained virological response

p1 - comparison between before treatment and at the end of treatment

p2 - comparison between before treatment and at SVR

p3 - comparison between before treatment and at 1 year after inclusion

p4 - comparison between end of treatment and 1 year after inclusion

Table 5. Comparison of serum hyaluronic acid at one year after inclusion between the two studied groups

\begin{tabular}{lcccc}
\hline Hyaluronic acid $(\mu \mathrm{g} / \mathrm{dl})$ & $\begin{array}{c}\text { Group } 1(n=150) \\
\text { Mean } \pm \text { SD }\end{array}$ & $\begin{array}{c}\text { Group } 2(n=150) \\
\text { Mean } \pm \text { SD }\end{array}$ & Mann-Whitney test & $P$ value \\
\hline 1 year after inclusion & $143.3 \pm 123.9$ & $126.4 \pm 136.9$ & 2.12 & $0.034^{*}$ \\
\hline
\end{tabular}

Table 6. Comparison of FIB-4 at end of treatment and one year after inclusion between the two studied groups

\begin{tabular}{lcccc}
\hline FIB-4 & $\begin{array}{c}\text { Group } 1(n=150) \\
\text { Mean } \pm \text { SD }\end{array}$ & $\begin{array}{c}\text { Group } 2(n=150) \\
\text { Mean } \pm \text { SD }\end{array}$ & Mann-Whitney test & P value \\
\hline End of treatment & $2.54 \pm 2.18$ & $2.07 \pm 1.84$ & 1.83 & 0.066 \\
\hline 1 year after inclusion & $2.76 \pm 2.46$ & $2.40 \pm 2.74$ & 1.36 & 0.103 \\
\hline
\end{tabular}

\section{Discussion}

Liver fibrosis is considered excessive wound healing due to chronic inflammation which leads to accumulation of extracellular matrix [16]. Patients with fibrotic liver may have increased mortality. However, the mortality rate increases significantly once cirrhosis, the end stage of fibrosis, is established [17], as there is no effective treatment [18]. Thus it is important to efficiently stage fibrosis to diagnose the severity of liver disease ruling out cirrhosis [17], and in addition follow up the patients during the treatment [19].

Liver biopsy was considered main paradigm for diagnosis of liver necro-inflammation and fibrosis. However, due to some complications and limitations in its performance, its efficacy for diagnosis and continuous monitoring of liver injury is questioned [20].

Hence, non-invasive biomarkers were increasingly considered for assessment of liver fibrosis. They could be direct biomarkers reflecting extracellular matrix turnover such as HA or indirect biomarkers reflecting alteration of liver function [21].

Hyaluronic acid is an essential component of extracellular matrix in many tissues in the body. In the liver,
HA is mostly synthesized by hepatic stellate cells [22]. As there is continuous hepatic stellate cell activation during chronic HCV infection, HA synthesis increases, rendering $\mathrm{HA}$ a candidate for evaluating liver fibrosis [23].

In our study, we found that HA could discriminate between mild fibrosis vs. moderate to advanced fibrosis. Also previous studies conducted by Halfon et al. [24], Fontana et al. [25] and Matsue et al. [26] showed that serum HA levels could exclude cirrhosis as it can distinguish between mild fibrosis and advanced fibrosis in chronic HCV patients.

Mihaylov et al. [27] stated that HA could be used as in clinical practice to exclude advanced fibrosis because of its high negative predictive value (98-100\%); thus it is the most accurate marker predicting advanced fibrosis in chronic hepatitis $\mathrm{C}$ and $\mathrm{B}$, steatosis and alcoholic liver disease.

In addition, in a cohort study by Patel et al. [28] a combination of HA, tissue inhibitor of metalloproteinases-1 (TIMP-1) and a2-macroglobulin was evaluated. It was found that the three-marker panel had good diagnostic accuracy and reasonable predictive values for the detection of moderate to severe stages of fibrosis in chronic hepatitis C. 
Also, a systematic review confirmed that HA offered potential as a prognostic or diagnostic indicator for liver cirrhosis manifestation, progression, or both [23].

Additionally, we found that DAA therapy alone or in combination with silymarin resulted in significant reduction in serum HA level.

Previously, Ishibashi et al. [29] and Yamada et al. [30] evaluated HA in responders and non-responders to HCV treatment. It was found that there was a significant decrease of serum HA levels at the end of follow-up in sustained complete responders to interferon $\alpha-2 a$ (INF- $\alpha$-2a) plus ribavirin therapy.

However, a study by Granot et al. [31] reported that monitoring of HA levels at initiation and during the course of antiviral therapy cannot help to predict response, but is a useful factor in assessing liver fibrosis.

A study conducted by El-Sisi and Zakaria [32] investigated the influence of direct acting drugs (SOF and DAC) on liver fibrosis in rats produced by $\mathrm{CCl} 4$ (as a nonHCV model). It was noted that DAA improved HA levels in CCl4induced fibrosis. DAAs also inhibited HSC activation. Thus they suggested that direct acting drugs (SOF and DAC) could ameliorate fibrosis independent of HCV eradication.

Furthermore, a study by Hansen et al. [33] stated that HA could significantly improve prognostic ability of baseline liver stiffness for predicting mortality and cirrhosis. This could help in estimation of urgency of treatment and patients who could benefit the most from antifibrotic drugs.

Also, we noted that patients who received the DAA plus silymarin combination showed a statistically significantly greater reduction in serum HA level compared to patients who received DAA alone. However, this was not the case when studying FIB4.

Large prospective studies encouragingly reported that HCV cure is durable in more than $99 \%$ of patients who were followed up for $\geq 5$ years, so relapse should not be expected. Administration of highly effective DAAs combined with these enduring, long-term results will result in a large and expanding pool of cured HCV patients [34].

Abdelsameea et al. found that delta transient elastography change in the responders to DAAs was significantly higher than the change in PEG/RBV responders and PEG/RBV nonresponders. The percentage of patients with regression of liver fibrosis was higher in DAAs responders $(52.5 \%)$ compared to $\mathrm{PEG} / \mathrm{RBV}$ responders (23.3\%) [35].

Shiha et al. reported that $48.7 \%$ of cirrhotic patients who received DAAs showed regression of fibrosis during follow-up after achieving SVR while 51.3\% (889 patients) remained stationary without change in their fibrosis stage [36].
Flisiak et al. reported a significant decline in mean liver stiffness value $(3.9 \mathrm{kPa})$ with follow-up after 2 years. Also, reduction of liver stiffness after efficient HCV infection therapy was reported in several studies with both interferon-based therapy and DAAs [37].

In contrast, Fried et al. conducted a randomized controlled trial on 154 persons with chronic HCV infection to determine the effect of a high dose of silymarin on liver disease activity after unsuccessful treatment with interferon-based therapy. The results showed insignificant changes in liver function parameters and HCV RNA; thus, the authors concluded that improvement in hepatic histology or in hepatic fibrosis (as measured by noninvasive serum markers or transient elastography) would have been unlikely [38].

Thus, HA could be a reliable, sensitive marker for monitoring fibrosis regression in chronic HCV patients treated with direct acting drugs. Adding silymarin to treatment protocols may slightly improve fibrosis reversion, protecting HCV patients from complications of cirrhosis. This issue needs further study on a large group of patients for a longer time of follow-up to determine whether fibrosis regression is related to the direct effect of medication or resolution of the HCV infection.

\section{Disclosure}

The authors declare no conflict of interest.

\section{References}

1. Abozeid M, Alsebaey A, Abdelsameea E, et al. High efficacy of generic and brand direct acting antivirals in treatment of chronic hepatitis C. Int J Infect Dis 2018; 75: 109-114.

2. Hashem M, Zaghla H, Zakaria Z, et al. High spontaneous clearance of symptomatic iatrogenic acute hepatitis $C$ genotype 4 infection. J Med Virol 2018; 90: 1841-1847.

3. Pawlotsky JM. Hepatitis C virus resistance to direct-acting antiviral drugs in interferon-free regimens. Gastroenterology 2016; 151: 70-86.

4. Falade-Nwulia O, Suarez-Cuervo C, Nelson DR, et al. Oral direct-acting agent therapy for hepatitis c virus infection: A systematic review. Ann Intern Med 2017; 166: 637-648.

5. Majumdar A, Kitson MT, Roberts SK. Systematic review: current concepts and challenges for the direct-acting antiviral era in hepatitis C cirrhosis. Aliment Pharmacol Ther 2016; 43: 12761292.

6. Essa M, Sabry A, Abdelsameea E, et al. Impact of new direct-acting antiviral drugs on hepatitis $\mathrm{C}$ virus-related decompensated liver cirrhosis. Eur J Gastroenterol Hepatol 2019; 31: 53-58.

7. Tacke F, Trautwein C. Mechanisms of liver fibrosis resolution. J Hepatol 2015; 63: 1038-1039.

8. Tsochatzis EA, Crossan C, Longworth L. Cost-effectiveness of noninvasive liver fibrosis tests for treatment decisions in patients with chronic hepatitis C. Hepatology 2014; 3: 832-843.

9. Ferenci P. Silymarin in the treatment of liver diseases: What is the clinical evidence? Clin Liver Dis 2016; 7: 8-10. 
10. Féher J, Lengyel G. Silymarin in the prevention and treatment of liver diseases and primary liver cancer. Curr Pharm Biotechnol 2012; 13: 210-217.

11. Chin JL, Pavlides M, Moolla A, Ryan JD. Non-invasive markers of liver fibrosis: adjuncts or alternatives to liver biopsy? Front Pharmacol 2016; 7: 159.

12. Orasan OH, Ciulei G, Cozma A, et al. Hyaluronic acid as a biomarker of fibrosis in chronic liver diseases of different etiologies. Clujul Med 2016; 89: 24-31.

13. European Association for the Study of the Liver. EASL recommendations on treatment of hepatitis C 2018. J Hepatol 2018; 68: 1-51.

14. Sterling RK, Lissen E, Clumeck N, et al. Development of a simple noninvasive index to predict significant fibrosis inpatients with HIV/HCV co-infection. Hepatology 2006; 43: 1317-1325.

15. Sebastiani G, Gkouvatsos K, Pantopoulos K. Chronic hepatitis C and liver fibrosis. World J Gastroenterol 2014; 20: 11033-11053.

16. Bataller R, Brenner DA. Liver fibrosis. J Clin Invest 2005; 115: 209-218.

17. Sharma S, Khalili K, Nguyen GC. Non-invasive diagnosis of advanced fibrosis and cirrhosis. World J Gastroenterol 2014; 20: 16820-16830

18. Weiskirchen R, Tacke F. Liver fibrosis: from pathogenesis to novel therapies. Dig Dis 2016; 34: 410-422.

19. Resino S, Bellon JM, Asensio C, et al. Can serum hyaluronic acid replace simple non-invasive indexes to predict liver fibrosis in HIV/Hepatitis C coinfected patients? BMC Infect Dis 2010; 10: 244.

20. Lambrecht J, Verhulst S, Mannaerts I, et al. Prospects in non-invasive assessment of liver fibrosis: Liquid biopsy as the future gold standard? Biochim Biophys Acta Mol Basis Dis 2018; 1864 (4 Pt A): 1024-1036.

21. Babaei Z, Parsian H. Hyaluronic acid algorithm-based models for assessment of liver fibrosis: translation from basic science to clinical application. Hepatobiliary Pancreat Dis Int 2016; 15: 131-140.

22. Rostami S, Parsian H. Hyaluronic acid: from biochemical characteristics to its clinical translation in assessment of liver fibrosis. Hepat Mon 2013; 13: e13787.

23. Neuman MG, Cohen LB, Nanau RM. Hyaluronic acid as a noninvasive biomarker of liver fibrosis. Clin Biochem 2016; 49: 302-315.

24. Halfon P, Bourlière M, Pénaranda G, et al. Accuracy of hyaluronic acid level for predicting liver fibrosis stages in patients with hepatitis C virus. Comp Hepatol 2005; 4: 6.

25. Fontana RJ, Goodman ZD, Dienstag JL, et al. Relationship of serum fibrosis markers with liver fibrosis stage and collagen content in patients with advanced chronic hepatitis C. Hepatology 2008; 47: 789-798.

26. Matsue Y, Tsutsumi M, Hayashi N, et al. Serum osteopontin predicts degree of hepatic fibrosis and serves as a biomarker in patients with hepatitis C virus infection. PLoS One 2015; 10: e0118744.

27. Mihaylov R, Pencheva B, Stoeva D, et al. Non-invasive diagnostics of liver fibrosis. Acta Medica Bulgarica 2017; 44: 50-56.

28. Patel K, Gordon SC, Jacobson I, et al. Evaluation of a panel of non-invasive serum markers to differentiate mild from moderate-to-advanced liver fibrosis in chronic hepatitis $\mathrm{C}$ patients. J Hepatol 2004; 41: 935-942.

29. Ishibashi K, Kashiwagi T, Ito A, et al. Changes in serum fibrogenesis markers during interferon therapy for chronic hepatitis type C. Hepatology 1996; 24: 27-31.
30. Yamada M, Fukuda Y, Koyama Y, et al. Serum hyaluronic acid reflects the effect of interferon treatment on hepatic fibrosis in patients with chronic hepatitis C. J Gastroenterol Hepatol 1996; 11: 646-651.

31. Granot E, Shouval D, Ashur Y. Cell adhesion molecules and hyaluronic acid as markers of inflammation, fibrosis and response to antiviral therapy in chronic hepatitis $\mathrm{C}$ patients. Mediators Inflamm 2001; 10: 253-258.

32. El-Sisi AE, Zakaria S. Potential anti-fibrotic effect of direct acting antiviral drugs on $\mathrm{CCl} 4$ induced hepatic fibrosis in rats. Egypt J Basic Clin Pharm 2019; 9: 101414.

33. Hansen JF, Christiansen KM, Staugaard B, et al. Combining liver stiffness with hyaluronic acid provides superior prognostic performance in chronic hepatitis C. PLoS One 2019; 14: e0212036.

34. Loo N, Hanysak B, Mann J, et al. Real-world observational experience with direct-acting antivirals for hepatitis $\mathrm{C}$ : baseline resistance, efficacy, and need for long-term surveillance. Medicine (Baltimore) 2019; 98: e16254.

35. Abdelsameea E, Alsebaey A, Abdel-Samiee M, et al. Direct acting antivirals are associated with more liver stiffness regression than pegylated interferon therapy in chronic hepatitis $\mathrm{C} \mathrm{pa-}$ tients. Expert Rev Anti Infect Ther 2021; 19: 1053-1059.

36. Shiha G, Mousa N, Soliman R, et al. Incidence of HCC in chronic hepatitis $C$ patients with advanced hepatic fibrosis who achieved SVR following DAAs: A prospective study. J Viral Hepat 2020; 27: 671-679.

37. Flisiak R, Janczewska E, Łucejko M, et al. Durability of virologic response, risk of de novo hepatocellular carcinoma, liver function and stiffness 2 years after treatment with ombitasvir/ paritaprevir/ritonavir \pm dasabuvir \pm ribavirin in the AMBER, real-world experience study. J Viral Hepat 2018; 25: 1298-1305.

38. Fried MW, Navarro VJ, Afdhal N, et al. Effect of silymarin (milk thistle) on liver disease in patients with chronic hepatitis $\mathrm{C}$ unsuccessfully treated with interferon therapy: a randomized controlled trial. JAMA 2012; 308: 274-282. 